\title{
The effects of highway development on housing prices
}

\author{
Or Levkovich $\cdot$ Jan Rouwendal $\cdot$ Ramona van Marwijk
}

Published online: 12 February 2015

(C) The Author(s) 2015. This article is published with open access at Springerlink.com

\begin{abstract}
The purpose of this research is to estimate the effects of highway development projects on the price of housing. Transportation development projects, highways in particular, improve a certain area's accessibility but also increase its levels of exposure to traffic intensity and noise pollution. These externalities are evaluated by homeowners and residents and are reflected in the price of housing. In this paper, we use several repeat sales model specifications, including difference-in-differences estimators, and control for neighborhood effects to examine housing price trends in the municipalities around two newly developed highways in the Netherlands. The results of the research demonstrate that changes in accessibility result in a significant positive effect on the price of housing in nearby municipalities, but that increased noise pollution and traffic intensity levels result in a decrease in prices. The findings also confirm that combining the total effects of all externalities, the effect of highway development on the price of housing is generally positive, and this effect is salient even before the project is completed due to public anticipation effects.
\end{abstract}

Keywords Highways - Accessibility · Property values $\cdot$ Housing price $\cdot$ Repeat-sales method

O. Levkovich $(\bowtie) \cdot$ J. Rouwendal

Department of Spatial Economics, VU University, Amsterdam, Netherlands

e-mail: o.d.levkovich@vu.nl

J. Rouwendal

e-mail: j.rouwendal@vu.nl

R. van Marwijk

Kadaster/Netherlands Cadastre, Land Registry and Mapping Agency, Apeldoorn,

Netherlands

e-mail: ramona.vanmarwijk@kadaster.nl 


\section{Introduction}

Transportation infrastructure development is undertaken to improve accessibility at a regional or urban level and to relieve traffic congestion in these areas. This development is evaluated by property owners and residents in the affected areas, and is capitalized in the price of housing. However, the effect of new transportation development, roads or highways in particular, may have both positive and negative effects on the price of housing. Improved accessibility may shift housing prices upwards, whereas higher traffic noise levels and increase in traffic density may reduce prices in houses that are adjacent to the new road. Gaining an understanding of whether a development project is valued positively or negatively is a key issue in evaluating regional policy. Accurate estimations of such valuations may be used as a valuable criterion in a social cost-benefit analysis. Analyzing the effects of the various positive and negative externalities of the development project may also be used in project evaluation, and assessing which externality is most dominant and to what extent it affects housing prices has implications for future policy planning. The relevance of the research is highlighted by the disagreement among researchers concerning the total effects of transportation development on housing prices. Although researchers generally agree that positive and negative externalities exist at different proximities to a developed road, most findings differ to the extent that some reach opposite conclusions.

In this paper, we apply a repeat sales and difference-in-differences method to investigate housing price dynamics following the development of two highways in the east of the Netherlands. We use a very large and unique housing transaction data from Kadaster, the Dutch Land Registry, which allows us to compare the development of housing transaction values over a long time-span and a large geographic area. The use of such data is essential for conducting a high-quality repeat-sales analysis, and it allows us to effectively control for housing and neighborhood characteristics which remain constant over time and to reduce concerns for omitted variable bias.

In the scope of the analysis, we focus on three main transportation development externalities: improved accessibility, increased traffic intensity and reduced noise levels. We argue that the effects of transportation infrastructure development on the price of housing vary between properties depending on their geographic location, municipality affiliation and proximity to the newly developed projects, and also on unobserved heterogeneity between properties. Our research focuses on several questions regarding the effect of transportation development on the price of housing. We first ask how infrastructure development is valued by owners and residents of the region's municipalities, and how they value the changes in the levels of each externality. In addressing this question, we estimate the elasticity of housing prices with respect to changes in accessibility, traffic intensity and noise pollution levels, and calculate the implicit willingness to pay (WTP) for changes in the levels of these externalities. The second question that is addressed in this research is how the strength and dominance of the effect of each of the transportation development externalities examined varies between different areas. As it is probable that transportation development affects housing prices differently in various geographic settings, such as in areas with differences in population densities, we control for differences between neighborhoods when estimating the effects of the highway development. Finally, considering all possible effects on housing prices, we estimate the total housing price effect in the affected municipalities and examine whether it has increased or decreased due to the construction of a new road. In addition, we use our estimation results to calculate WTP for accessibility improvements for each four-digit postal code in the study area. 
The paper is structured as follows. The next section contains a literature review. The "Model specifications" section describes the data sources and data sets used in the research. The "Data description and summary statistics" section presents the model specifications. The "Estimation results" section describes the results of the estimations and includes a discussion of the results. In the "Conclusions and discussion" section, we calculate quasi-rents and WTP values for improved accessibility. Finally, the seventh section includes a conclusion and discussion regarding possible policy applications.

\section{Literature review}

The development of transportation infrastructure and the resulting drop in transportation costs and increase in accessibility levels are closely related to changes in housing values (Alonso 1964). In the housing market literature, hedonic regressions are most commonly used to determine the price of a property as a function of its attributes (Rosen 1974). The repeat sales method (Bailey et al. 1963) can be used as a modification of hedonic models, as well as to measure changes in a price of the same property sold over time. Originally developed as a method to construct price indices, the main advantage of the repeat sales method is that it allows fixed characteristics that influence property prices and were perhaps omitted from the hedonic regression to be ignored. Due to the wide application of both methods, different improvements have been introduced to address various challenges posed by the housing market and to reduce estimator bias (Wang and Zorn 1997). One example is the use of the weighted repeat sales method, which was developed by Case and Shiller (1987); this approach considers changes in the variance of the error between observations and therefore yields more accurate estimations of housing price indices.

To estimate the effect of external development or "treatment" on a group of houses, the difference-in-differences (DID) estimator may be incorporated as part of the repeat sales model (Imbens and Wooldridge 2009). The DID estimator is used to compare the time effect between a group that was exposed to a treatment and a control group. The difference in time that is observed in the control group is then subtracted from the time of the treatment group to separate unrelated time appreciation effects from treatment effects. The inclusion of a DID estimator requires that the control and treatment groups are properly defined to reduce the likelihood of bias in the estimated coefficient (Imbens and Wooldridge 2009).

The effects of transportation development on housing prices, in particular in relation to accessibility, have been addressed extensively in previous literature, predominantly using estimations of hedonic models (Armstrong and Rodríguez 2006; Cheshire and Sheppard 1995; Coulson and Engle 1987; Franklin and Waddell 2003; Henneberry 1998; Iacono and Levinson 2011; Martínez and Viegas 2009). Whereas most of these studies focus exclusively on the positive effects of improved accessibility on housing prices, other studies emphasize that both positive and negative externalities may result from highway development, and these may affect residential preferences (Debrezion et al. 2007; Iacono and Levinson 2011; Martínez and Viegas 2009; Tillema et al. 2012). Moreover, depending on the exposure levels to different externalities, house prices in different geographic areas may change differently due to the effects caused by the new transportation infrastructure development (Smersh and Smith 2000). Negative effects may result from an increase in traffic noise pollution, which has also been found to be a cause of discount in the value of properties that are located along a newly developed highway (Kim et al. 2007; Nelson 1982; Theebe 2004; Wilhelmsson 2000). Ossokina and Verweij (2011) study the effects of 
a new highway in The Hague on the surrounding residential properties using a repeat sales approach and focus particularly on the positive effects of the reduced traffic density. They find that property values in the proximity of the new road have increased with the reduction in traffic density, thus providing further evidence that homeowners value traffic density negatively. The effects of a new transportation development project have also been found to be reflected in housing prices even before its completion. Yiu and Wong (2005), Koster et al. (2010) and Cotteleer and Peerlings (2011) demonstrate that prices may adjust before project completion and that rational public expectations may account for the price capitalization of the new highway while it is still under construction.

The past literature raises several important issues. First, it highlights that a different focus on the positive or negative externalities of a transportation development can lead to differences in conclusions. Although researchers generally agree that positive and negative externalities exist at different proximities to the new or reconstructed road, most findings raise the suspicion of omitted variable bias as they do not consider the different effects of each externality over time and space. Other possible explanations for the difference in the dominance of externalities in the housing market may be the improper definition of control and treatment groups, or the spatial patterns of the sampled data. As demonstrated by Smersh and Smith (2000), the dominance of the effect of one externality over another depends greatly on the different spatial patterns in the sampled areas. Moreover, the past literature also shows that the design of the model requires special attention to avoid bias in the coefficients and to estimate properly the different effects on housing prices.

In this paper, we address these challenges by estimating the effects of the development of two highways in the Netherlands on local housing prices using a repeat sales analysis combined with a DID approach. Aiming to reduce the suspicion of estimator bias, our analysis also considers that both positive and negative effects may be apparent in different municipalities in the environs of the highways. Furthermore, we take neighborhood effects into account and consider that prices may change prior to the completion of the highway development due to anticipation effects.

\section{Model specifications}

To determine the effects of transportation infrastructure development, we estimate three different versions of the repeat sales model. The three specifications correspond to the research questions and are used for comparison of the estimated coefficients and of model robustness. The repeat sales model specifications that we propose to use are: (i) the traditional repeat sales model, including a DID estimator; (ii) a specification that accounts for the three main transportation externalities and controls for neighborhood effects; (iii) a specification that estimates the individual externality effects for each municipality. To control for spatial correlation in the residuals, the models are estimated using clustered standard errors, in which the clusters are defined based on six-digit postal codes. All suggested model forms derive from the traditional repeat sales form, introduced by Bailey et al. (1963):

$$
\log \widetilde{P_{i}^{T, t}}=\beta^{T}-\beta^{t}+\varepsilon_{i}^{T, t}
$$

where $\widetilde{P_{i}^{T, t}}=\left(\frac{P_{i T}}{P_{i t}}\right)$ is the change in price of house $i$ between times $t$ and $T$. $\beta^{T}-\beta^{t}$ is the change in the repeat sales price index between the time of the second and first sale of the house. As an addition to this model, we incorporate DID estimators as an interaction variable, which 
indicates that property $\mathrm{i}$ is located in the treatment area and was sold for the first time before the treatment period and for the second time during the treatment period. $\left(T_{i}=1\right)\left(G_{i}=1\right)$ : $I_{i}=T_{i} \times G_{i}$ The model specification also takes anticipation effects into account. As the construction of both projects began in 2001, the anticipation period was set to begin in the year 2000 to capture the full effects of public expectation. It is likely that public anticipation in relation to the development of the projects began slightly before the start of construction, and therefore properties that were sold between the years 2000-2004 were included in the anticipation period. The period 1995-1999 is defined as the control period. Thus:

$$
\log \widetilde{P_{i}^{T, t}}=\beta^{T}-\beta^{t}+\tau_{\text {treatment }} \times\left(I_{i}^{T}-I_{i}^{t}\right)+\tau_{\text {ant }} \times\left(J_{i}^{T}-J_{i}^{t}\right)+\varepsilon_{i}^{T, t}
$$

where $I_{i}^{T}$ represents an indicator variable that is equal to 1 if a property is located in the treatment area and the second transaction took place in the treatment period ( $>$ July 2004), and is equal to zero otherwise. $J_{i}^{T}$ represents an indicator variable that is equal to 1 if a property is located in the treatment area and the second transaction took place in the anticipation period (2000-2004), and is equal to zero otherwise. We define analogous symbols $I_{i}^{t}$ and $J_{i}^{t}$ which indicate whether a property is located in the treatment area and the first property transaction occurred during the treatment period or the anticipation period respectively. If a property is located outside the treatment area, the expression $\left(I_{i}^{T}-I_{i}^{t}\right)$ takes the value of zero. It is also zero for properties inside the treatment area if both sales occurred before the treatment period, or if both sales occurred during the treatment period. In this manner, we consider the treatment effect only once for each property $i$. $\tau_{\text {treatment }}$ is then interpreted as the overall effect of the new transportation development on the price of housing, including observed and unobserved factors. $\tau_{\text {ant }}$ reflects the effects of "anticipation" for the new highway, as capitalized in the housing transaction prices.

The second specification we use is focused on identifying the effects of the three main externalities of transportation development observed in this research: improved accessibility, and increased traffic intensity and noise pollution. The model specification below is a modification of Eq. (2) in the sense that three variables are added to describe changes between time periods in the levels of the externalities mentioned above:

$$
\begin{aligned}
\log \widetilde{P_{i}^{T, t}}= & \beta^{T}-\beta^{t}+\mu_{1} \times \widetilde{W_{\text {noise }}^{t}}+\mu_{2} \times \log \left(\widetilde{W_{\text {acc }}^{T, t}}\right) \\
& +\mu_{3} \times \widetilde{W_{\text {dens }}^{T, t}}+\sum_{t=1}^{3} \sum_{j=1}^{N} \pi_{j}^{T} \times N_{j}^{T}+\varepsilon_{i}^{T, t}
\end{aligned}
$$

where $\widetilde{W_{\text {noise }}^{T, t}}=\left(W_{\text {noise }}^{T}-W_{\text {noise }}^{t}\right)$ is a dummy variable that is equal to 1 if a property is located within $300 \mathrm{~m}$ of the highway. As in the previous model specification, this expression becomes equal to zero if both transactions in period $T$ and $t$ have occurred after the completion of the highways in the summer of 2004. $\widetilde{W_{a c c}^{T, t}}=\frac{W_{a c c}^{T}}{W_{a c c}^{t}}$ indicates changes in accessibility levels. $\widetilde{W_{\text {dens }}^{T, t}}=\left(W_{\text {dens }}^{T}-W_{\text {dens }}^{t}\right)$ is a dummy variable that is equal to 1 if a property is located up to $1 \mathrm{~km}$ from a highway interchange. $\mu_{1}, \mu_{2}, \mu_{3}$ are estimated with respect to $W_{i}$, and measure the effect of changes in each of the externality levels on the price of housing. As the externality variables take a value different from zero only for treatment transactions, when changes in externality exposure levels occur, the corresponding estimators $\mu_{1}, \mu_{2}, \mu_{3}$ essentially function as DID estimators.

The effects of the externalities of new highway developments may differ over municipalities, depending on unobserved neighborhood characteristics (Martínez and Viegas 
2009). This issue is addressed by including a neighborhood interaction dummy, $N_{j}^{T}$, which indicates that property $i$ is located in municipality $j=1 \cdots N$, and was sold in period $t$, before, during or after the completion of the road. The estimator $\pi_{j}^{T}$ is not interpreted, as the latter term of the model is used to account for unobserved time trends in each of municipalities in the treatment area.

A key problem that arises from Eq. (3) is that the model may not sufficiently identify the differences in the marginal effects of the externalities between neighborhoods. For example, some neighborhoods may be more sensitive to one externality than another. In that case, it may be useful to use more than one estimator to explain the effects of changes in externality level. Therefore, Eq. (3) may be modified using a more flexible specification that is able to accommodate neighborhood differences in the estimated values. This may be done by interacting the neighborhood effects with the externality variables as specified in Eq. (4):

$$
\begin{aligned}
\log \widetilde{P_{i}^{T, t}}= & \beta^{T}-\beta^{t}+\sum_{j=1}^{N} \mu_{1, j} \times A_{i} \times \widetilde{W_{\text {noise }}^{T, t}}+\sum_{j=1}^{N} \mu_{2, j} \times B_{i} \times \log \left(\widetilde{W_{\text {acc }}^{T, t}}\right)+\sum_{j=1}^{N} \mu_{3, j} \times C_{i} \\
& \times \widetilde{W_{\text {dens }}^{T, t}}+\varepsilon_{i}^{T, t}
\end{aligned}
$$

Specification (4) aims to estimate individually the effects of the externalities in each of the municipalities in the treatment area. $A_{i}, B_{i}, C_{i}$ are dummy variables that indicate a specific municipality affiliation. Namely, we allow $\mu_{1, j}, \mu_{2, j}, \mu_{3, j}$ to be estimated separately for each municipality, thus permitting spatial flexibility between the estimated effects of each externality.

\section{Data description and summary statistics}

\section{Case studies}

To examine the effects of transportation infrastructure development, we use two case studies. The purpose of using two case studies is to increase the robustness of the results by increasing the available sample, and also to compare the effects of different highway development projects in relatively similar areas in terms of accessibility and population density. The projects chosen were those of the A30 and the A50 Rijkswegen (highways) in the east of the Netherlands, both completed in the summer of 2004 (see Figs. 1, 2, 3; Tables 8 and 9 in Appendix 1).

\section{Housing price data}

House transaction data were made available through Kadaster, the Dutch land registry. The data used in the research include all housing transactions in five Dutch provinces-NoordBrabant, Gelderland, Flevoland, Limburg, and Utrecht (excluding the city of Utrecht itself) —for the period 1995-2011. As the data are used exclusively for repeat sales analysis, which requires properties to be sold more than once, we include only housing transactions for properties that were sold twice or more-approximately 438,000 transactions, or $37 \%$ of the original data. 


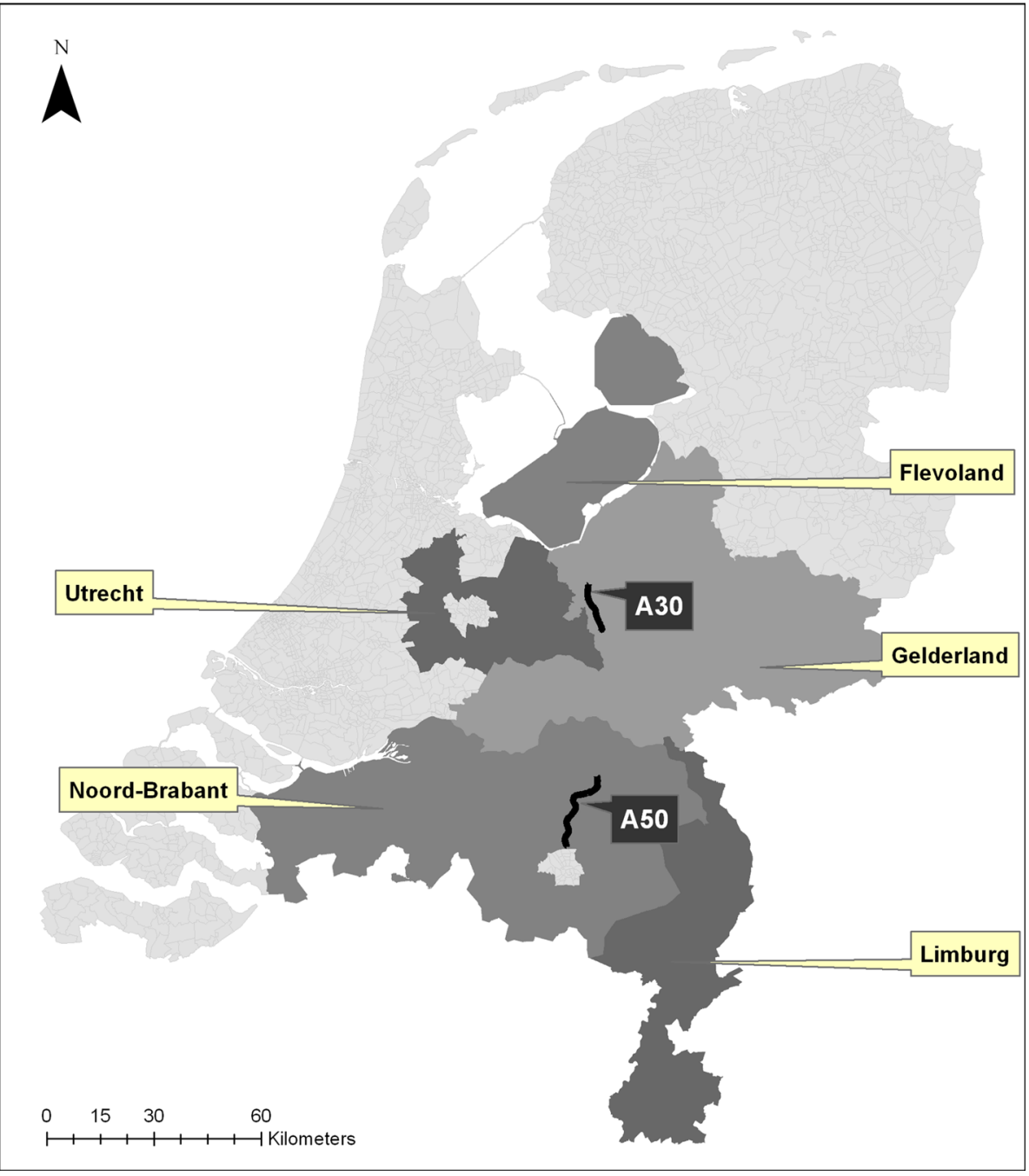

Fig. 1 Map of the study area

For the purpose of the control and treatment analysis, three time periods are defined, as follows: (i) "control period," 1995-1999 (before highway development began); (ii) "anticipation period," 2000-June 2004 (during highway development works); (iii) "treatment period," July 2004-2011 (after highway development ended). Summary statistics of the housing price data are specified in Table 1 and See Fig. 4 in Appendix 2.

Accessibility indicators and data

To compare accessibility levels between postal code areas over time, we use the economic potential indicator (see, for instance, Gutiérrez 2001; López et al. 2008; 


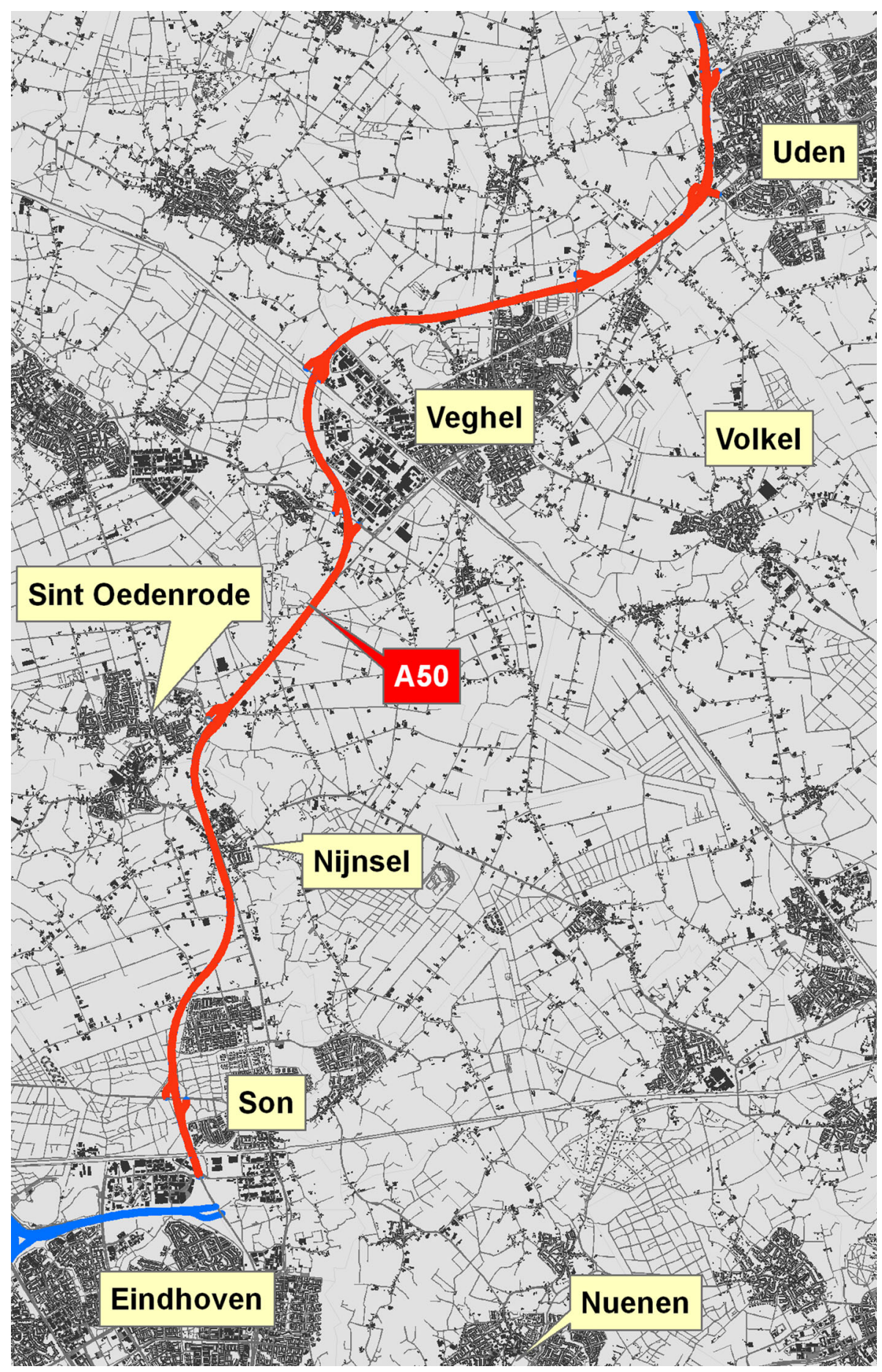

Fig. 2 Map of the A50 area 


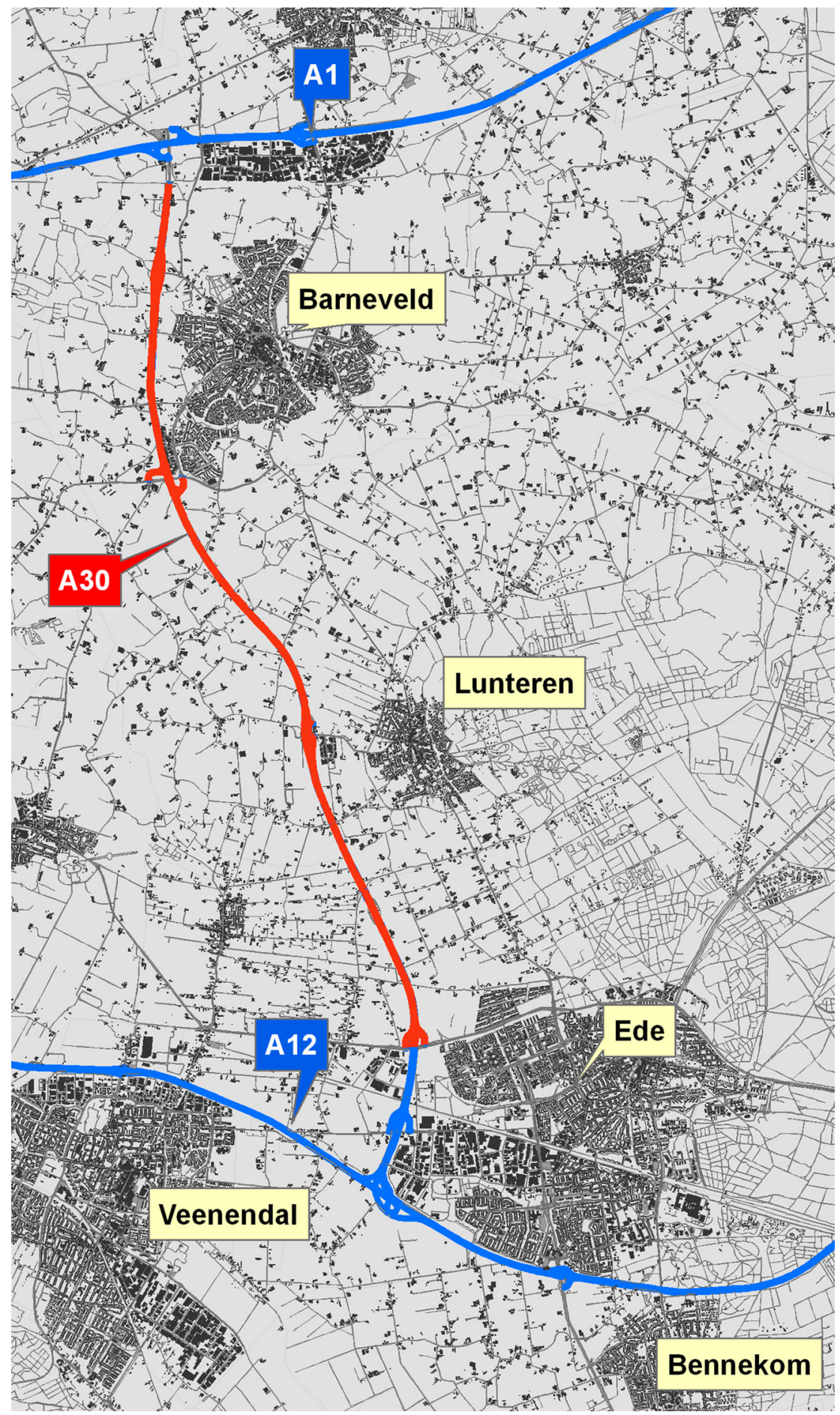

Fig. 3 Map of the A30 area 
Table 1 House transaction prices-summary statistics (Values in Euro 1995-2011)

\begin{tabular}{llrrrr}
\hline Year & N & \multicolumn{1}{l}{ Mean } & \multicolumn{1}{l}{ SD } & \multicolumn{1}{l}{ Min } & \multicolumn{1}{l}{ Max } \\
\hline 1995 & 22,007 & 97,508 & 43,784 & 25,071 & 726,048 \\
1996 & 25,928 & 108,272 & 50,073 & 25,185 & $1,361,341$ \\
1997 & 28,413 & 120,083 & 54,611 & 25,033 & $1,050,501$ \\
1998 & 30,167 & 132,365 & 64,160 & 25,461 & $1,815,121$ \\
1999 & 31,818 & 153,625 & 80,845 & 25,412 & $1,928,566$ \\
2000 & 30,579 & 177,628 & 95,485 & 25,226 & $1,633,609$ \\
2001 & 31,499 & 191,645 & 103,294 & 25,626 & $1,953,905$ \\
2002 & 30,414 & 202,205 & 104,736 & 25,000 & $1,816,028$ \\
2003 & 28,400 & 208,224 & 103,064 & 26,500 & $1,925,000$ \\
2004 & 27,013 & 215,623 & 108,342 & 25,000 & $1,930,000$ \\
2005 & 28,434 & 224,762 & 113,525 & 25,000 & $1,850,000$ \\
2006 & 28,577 & 235,472 & 120,459 & 27,500 & $1,875,000$ \\
2007 & 26,614 & 247,515 & 135,789 & 27,000 & $1,937,500$ \\
2008 & 23,723 & 253,800 & 139,564 & 25,000 & $2,000,000$ \\
2009 & 15,999 & 240,780 & 131,068 & 25,000 & $2,000,000$ \\
2010 & 15,022 & 241,178 & 132,545 & 29,000 & $1,950,000$ \\
2011 & 14,207 & 239,340 & 132,486 & 27,000 & $1,850,000$ \\
All & 438,814 & 189,616 & 113,827 & 25,000 & $2,000,000$ \\
\hline & & & & &
\end{tabular}

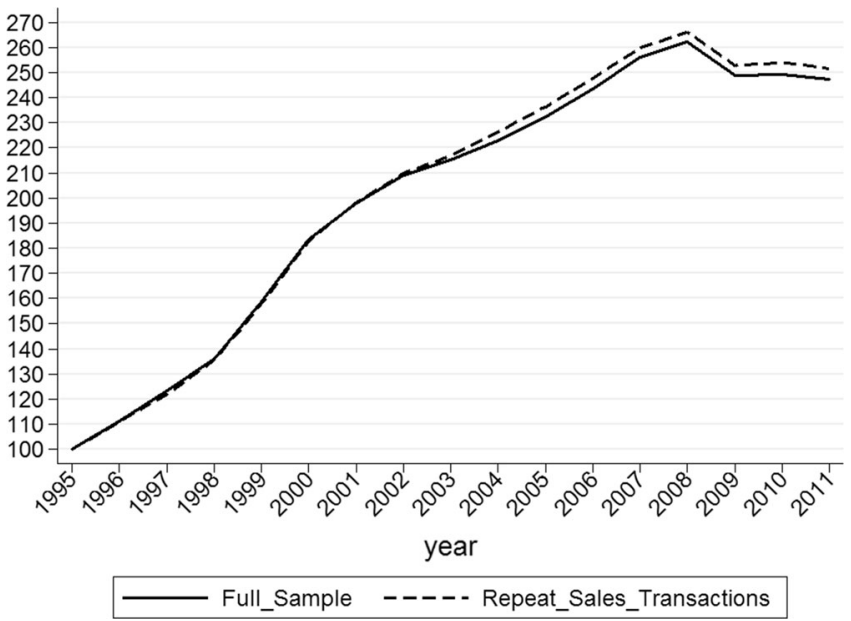

Fig. 4 Price indexes of the study area based on the full sample (solid line) and on the transactions which were valid for repeat sales analysis (dashed line). The similarity between the two indexes shows that repeatsales transactions do not demonstrate differences in trends of transactions values, and therefore reduces suspicions of a sample selection bias

Spiekermann and Neubauer, 2002; Vickerman et al. 1999). The economic potential indicator is originally derived from the gravity model and is formulated as follows: 


$$
A C C_{i}=\sum_{j=1}^{n} \frac{P_{j}}{I_{i j}^{\propto}}
$$

where $A C C_{i}$ is the economic potential accessibility of postal code area $i, I_{i j}$ represents the impedance level, scaled with the power $\alpha$, and $P_{j}$ represents the activity factor. In this research, the impedance function was constructed by using the expected road network travel time in seconds between each of the four-digit postal code (PC4) areas in the examined area in the Netherlands. Travel time was calculated from the center of the constructed area for each PC4 area using an open-street geographic information system. The activity element was computed based on population data in each PC4 area, which was available from the Dutch Central Bureau of Statistics (CBS). ${ }^{1}$

The economic activity potential indicator is also used in this research as it is suitable for the relatively large study area, which varies in terms of level of population density. As commonly used in the literature, we set the distance decay parameter to $\alpha=1$ (Bruinsma and Rietveld 1998; Gutiérrez 2001; Gutiérrez et al. 2010). Table 2 describes the changes in accessibility levels attributed to the completion of the new highways in each of the treatment municipalities.

Noise level data

The effects of traffic noise are limited to the local surroundings of the highway and they depend on factors such as traffic density and flows at each hour of the day, natural or planned noise barriers, and others. Therefore, in the absence of exact data measurements, it is difficult to determine the distance from the road up to which noise pollution is apparent. Wilhelmsson (2000) uses a noise model to argue that for distances less than $300 \mathrm{~m}$ from a road (in suburban areas in Sweden), the marginal contribution of traffic noise to the surrounding noise pollution is substantial. Theebe (2004) finds that noise pollution affects housing prices in the Amsterdam area only at levels above $55 \mathrm{~dB}$. Based on data from the Dutch Ministry of Infrastructure and Environment (RWS 2008, 2012), these noise levels exist up to roughly $200 \mathrm{~m}$ from the A30 and A50 roads, depending on the exact location. As it is difficult to determine the exact limit of the noise effects, we identify areas exposed to noise pollution levels using a distance dummy of $300 \mathrm{~m}$ from the road. It is worth noting that the A30 and the A50 are located in low population density areas and thus relatively few properties are observed within close distances of the highways (Table 3).

Traffic intensity data

Estimating the negative effects of increased traffic intensity on housing prices poses several challenges. First, increased levels of traffic intensity are closely related to increases in both noise and accessibility levels and can indirectly affect housing prices through these externalities. However, after controlling for changes in noise pollution and accessibility levels, traffic intensity may affect housing prices through its indirect effect on public health, road safety, and other factors (such as air pollution from traffic emissions, or general residential ambience). These effects are particularly local and predominate almost

\footnotetext{
1 In 2004, the year in which the highways were completed, there were 3,993 four-digit postal code areas in the Netherlands, which had between 50 and 22,860 inhabitants, with a maximum of approximately 11,685 households in the city of Amsterdam. The average PC4 area had 4,070 inhabitants, or 1,765 households per PC4 area.
} 
Table 2 Summary of changes in accessibility in the municipalities directly adjacent to the treatment areas

\begin{tabular}{|c|c|c|c|}
\hline Municipality & Postal code & Mean level of change in accessibility (\%) & Freq. \\
\hline \multicolumn{4}{|l|}{ A30 } \\
\hline Barneveld & 3771 & 2.84 & 913 \\
\hline Barneveld & 3772 & 3.00 & 889 \\
\hline Barneveld & 3773 & 2.34 & 416 \\
\hline Voorthuizen & 3781 & 2.19 & 746 \\
\hline Ede & 6711 & 2.15 & 885 \\
\hline Ede & 6712 & 2.49 & 549 \\
\hline Ede & 6713 & 1.70 & 1,389 \\
\hline Ede & 6714 & 2.60 & 832 \\
\hline Ede & 6715 & 2.04 & 695 \\
\hline Ede & 6716 & 2.28 & 1,340 \\
\hline Ede & 6717 & 2.55 & 1,816 \\
\hline Bennekom & 6721 & 2.70 & 1,315 \\
\hline Lunteren & 6741 & 3.12 & 720 \\
\hline Total A30 & & 2.44 & 12,505 \\
\hline \multicolumn{4}{|l|}{ A50 } \\
\hline Uden & 5401 & 10.40 & 950 \\
\hline Uden & 5402 & 10.32 & 568 \\
\hline Uden & 5403 & 8.10 & 1,143 \\
\hline Uden & 5404 & 10.97 & 298 \\
\hline Uden & 5406 & 10.08 & 224 \\
\hline Volkel & 5408 & 6.61 & 98 \\
\hline Veghel & 5463 & 6.01 & 733 \\
\hline Veghel & 5464 & 8.09 & 117 \\
\hline Veghel & 5465 & 8.89 & 20 \\
\hline Veghel & 5466 & 9.77 & 35 \\
\hline Veghel & 5467 & 5.88 & 1,129 \\
\hline Sint Oedenrode & 5491 & 6.72 & 688 \\
\hline Sint Oedenrode & 5492 & 6.27 & 394 \\
\hline Son & 5691 & 7.33 & 925 \\
\hline Total A50 & & 7.86 & 7,322 \\
\hline
\end{tabular}

Population growth rates were separated from the calculation of the changes in accessibility values noted here

exclusively in densely populated areas. Therefore, we define properties that are located within a distance of $1 \mathrm{~km}$ from a new highway interchange as being exposed to changes in traffic intensity levels as we assume that such properties in the immediate proximity of an interchange will be exposed to higher levels of traffic. The limit of $1 \mathrm{~km}$ was chosen based on the characteristics of the study area. In the study area, a $1 \mathrm{~km}$ distance from an interchange usually includes a limited number of regional roads that connect the highway interchanges to nearby towns. Also, this range is usually sufficiently broad to include a sufficient number of properties, but so large that it includes whole neighborhoods or overlaps areas influenced by other interchanges (See Figs. 5, 6 in Appendix 3). 
Table 3 Number of properties which are located within $300 \mathrm{~m}$ from a new highway, or $1 \mathrm{~km}$ from a new interchange

\begin{tabular}{lllll}
\hline & $\begin{array}{l}300 \mathrm{~m} \text { from a new } \\
\text { highway (Noise } \\
\text { pollution) }\end{array}$ & $\begin{array}{l}\text { Share of total } \\
\text { properties in a } \\
\text { municipality (\%) }\end{array}$ & $\begin{array}{l}1 \mathrm{~km} \text { from a new } \\
\text { interchange (Traffic } \\
\text { intensity) }\end{array}$ & $\begin{array}{l}\text { Share of total } \\
\text { properties in a } \\
\text { municipality (\%) }\end{array}$ \\
\hline Barneveld & 10 & 0.1 & 67 & 0.6 \\
Bennekom & - & - & - & - \\
Ede & 1 & 0.0 & 108 & 0.4 \\
Lunteren & - & - & 8 & 0.2 \\
Voorthuizen & - & - & - & - \\
A30 & 11 & & 183 & 1.0 \\
Sint & 19 & 0.3 & 69 & 0.4 \\
$\quad$ Oedenrode & & & & 1.4 \\
Son & 14 & 0.3 & 17 & 0.3 \\
Uden & 54 & 0.4 & 207 & - \\
Veghel & 1 & 0.0 & 27 & \\
Volkel & - & - & - & \\
A50 & 88 & & 520 & \\
Total & 99 & & 503 & \\
\hline
\end{tabular}

Transaction noted here are only those made in the 3rd period, during or after July 2004

Table 3 contains summary statistic for properties that are located in proximity of $1 \mathrm{~km}$ to a new $\mathrm{A} 30$ or A50 interchange.

Treatment and control areas

The treatment area is defined based on changes in accessibility level. Postal code areas that have experienced an increase of over $2.5 \%$ in accessibility level are defined as treatment areas. In our chosen study area, the five provinces in the south and west of the Netherlands, approximately $3 \%$ of postcodes meet this criterion. In relation to control area definitions, we use two scenarios based on aerial distance from the road or changes in accessibility levels. In the first scenario, referred to as the "distance study area," we arbitrarily define the control area as postal code areas that are located within $10 \mathrm{~km}$ of the development projects, excluding the city of Eindhoven (See Fig. 7 in Appendix 4). This definition is motivated by the assumption that postal code areas within this range share common spatial and housing market characteristics with the treatment area, while not all are influenced by the development of the highways. In the second scenario, referred to as the "accessibility study area," we define the control area as postal code areas that have experienced over $1.5 \%$ change in accessibility level (See Fig. 7 in Appendix 4). In the study area, approximately $20 \%$ of postal code areas meet this criterion. The advantage of using such an extensive control area is that it has a larger observation base of changes in accessibility levels. However, this definition may include areas that are too distant and different from the treatment area, which may result in a biased estimated effect. One notable disadvantage of both scenarios is that most postal code areas in the municipality of Ede are not included in the treatment area as they have experienced an accessibility level increase of less than $2.5 \%$ (see Table 2), but they are included in both control area scenarios. As Ede is located at the southern entrance of the A30 and is situated between two "treatment" 


\section{Changes in accessibility levels - South and East of The Netherlands}

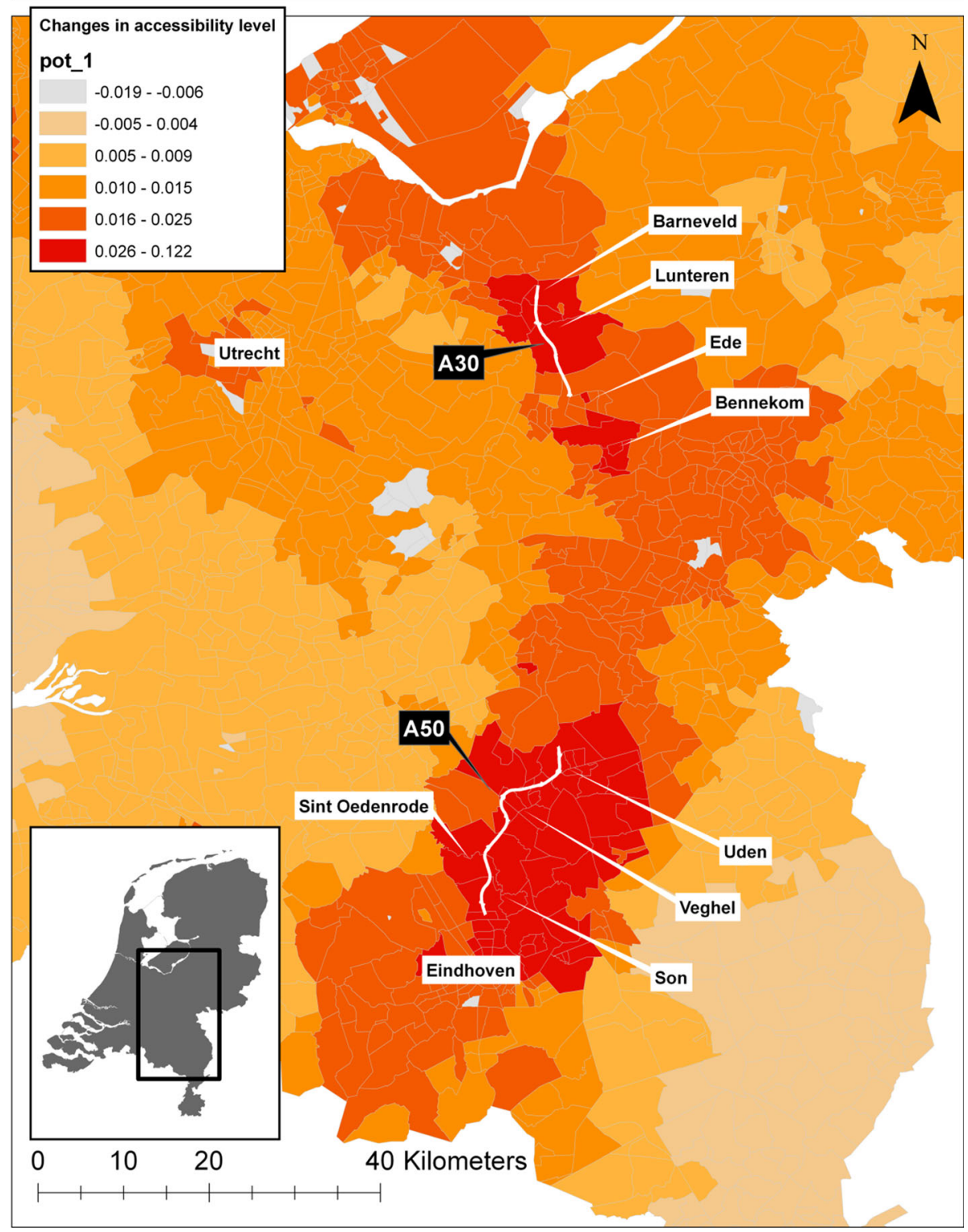

Fig. 5 Changes in levels of accessibility due to the development of the A30 and A50 highways. Economic potential indicator $(\alpha=1)$

municipalities, it can be argued that it cannot serve as an appropriate control area. However, excluding Ede from either control area did not cause a significant change in the DID coefficient values or in statistical significance levels, and thus it was left in the study as a control area. 


\section{Uden - Areas affected by the A50}

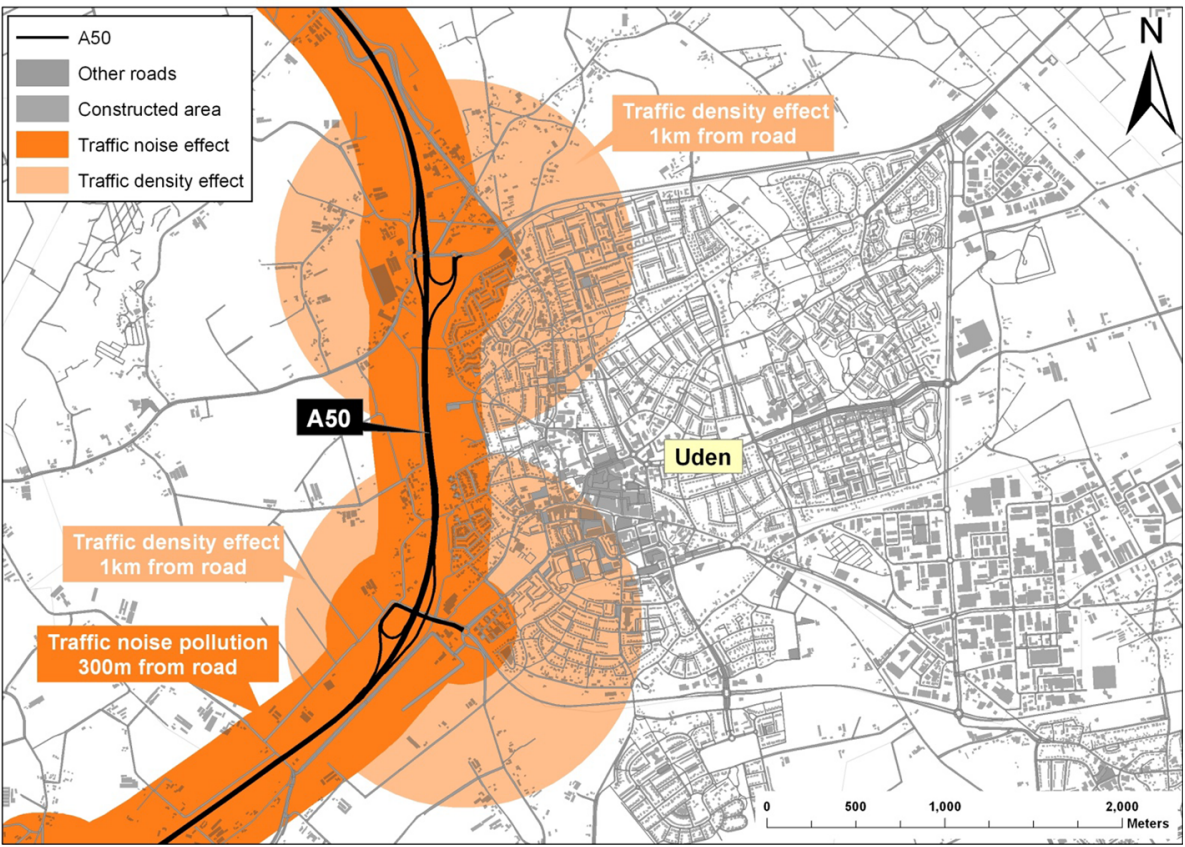

Fig. 6 Areas affected by negative externalities (Uden and Noord-Brabant)

\section{Estimation results}

Repeat sales and difference-in-difference (DID) estimators

The first specification to be estimated is the repeat sales model including the DID estimators, as specified in Eq. (2). The purpose of this specification is to address the question of how the development of the A30 and the A50 highways has affected housing prices in the nearby municipalities (see results in Table 4). The model was estimated using different DID estimators. The specifications reported in columns 1 and 2 include DID estimators for the treatment and anticipation effects for both highways under each treatment control area scenario. The specifications in column 3 and 4 include DID estimators for the treatment and anticipation effects for each highway individually under both treatment control area scenarios.

The results reveal several interesting findings. A notable finding is that almost all DID estimators are positive, significant, and their values remain relatively constant between each specification, and each treatment control area scenario. The fact that the coefficients and statistical significance levels vary relatively little between different definitions of control area indicates that the estimated results are quite robust. Combining the treatment in both highways (columns 1 and 2), we see that the effect of the new highways has increased housing values in the surrounding residential area by approximately $2.5-4.3 \%$. Moreover, prices increased by an even higher rate of approximately $5 \%$ before the highways were completed. This finding matches the assumption that the residents in the 


\section{Difference-in-Differences study area scenarios}
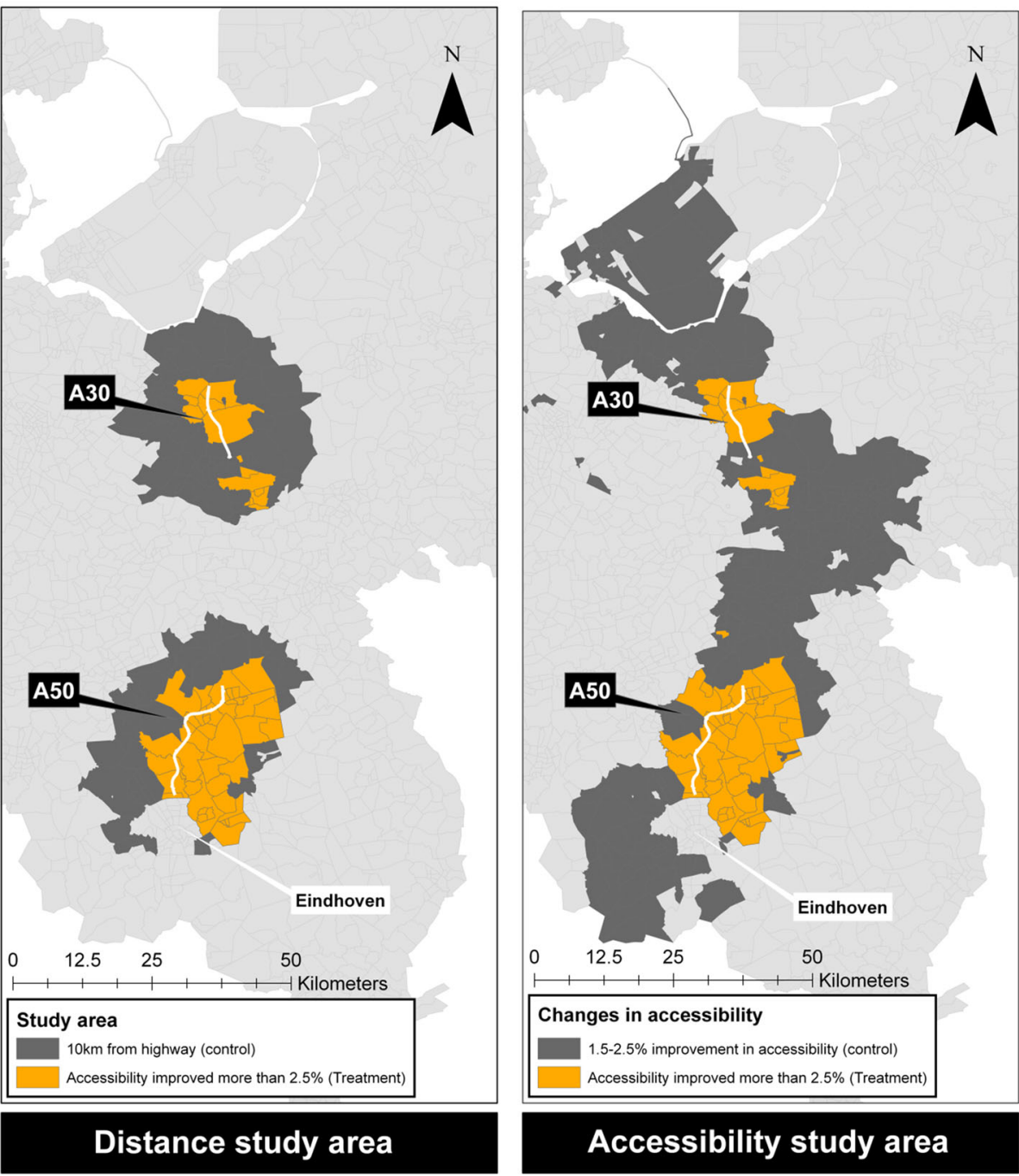

\section{Accessibility study area}

Fig. 7 Maps of the study area scenarios

treatment area attributed a positive value to the development of the highways and this is capitalized in the value of the residential properties. Second, the value of the DID estimator for the anticipation period is much higher than the value of the DID estimator for the treatment period. Two possible explanations can be provided for these results. First, this may suggest that the housing market in the treatment area anticipated the change in prices and began adjusting long before the roads were completed in 2004. Second, it may also be that before the completion of the highways, the public expected that the effects would mostly be positive (probably due to increased accessibility). However, after the completion of the projects, the negative effects of increased traffic and noise pollution would have 


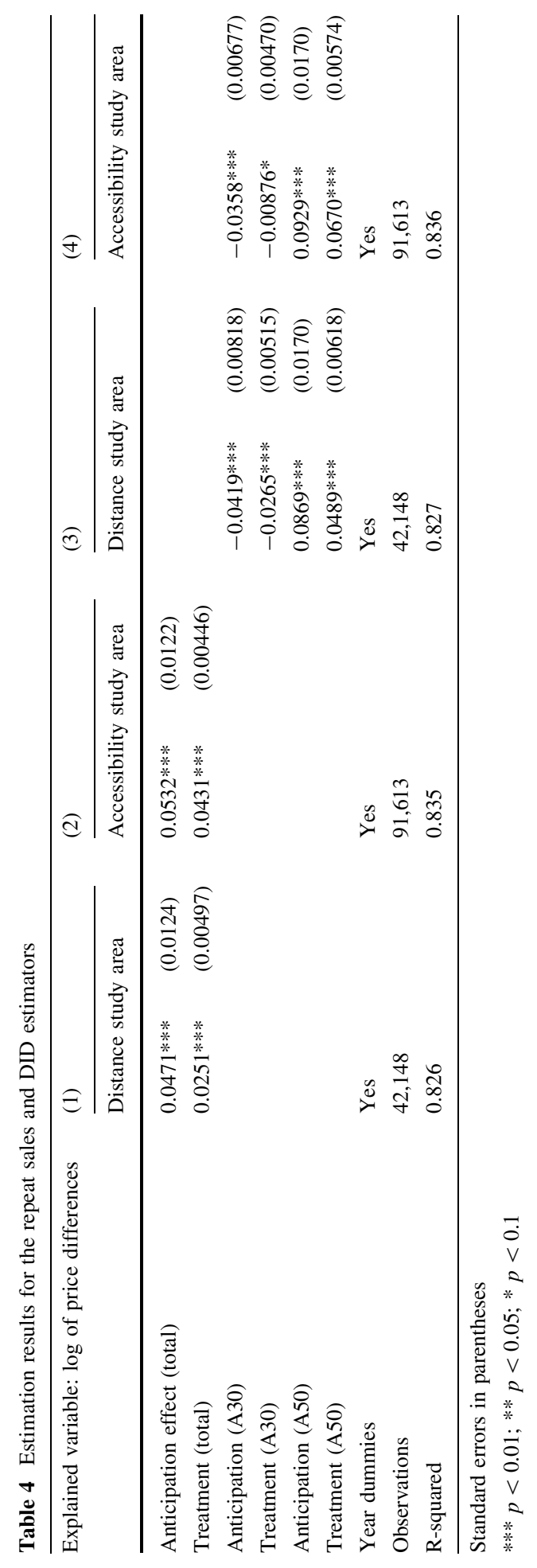


become apparent, and this is reflected by the lower values of the post-treatment DID estimators.

The results for the A50 (columns 3 and 4) match the expectation that houses in the treatment area would increase in value. Compared to both the distance and accessibilitybased control areas, houses that were sold during the four years prior to the completion of the A50 gained approximately $9 \%$ in value. After completion, the A50 added 4.9-6.7\% to the values of the houses in the nearby municipalities.

However, the estimated results for the A30 show an opposite and unexpected pattern. Compared to properties in the distance-based control area (within $10 \mathrm{~km}$ of the A30), houses in the municipalities along the A30 have not experienced an increase in value and the effect is estimated to be negative. Moreover, in the four years prior to the completion of the road, housing transactions were approximately $4 \%$ lower in value, implying a negative anticipation effect. A possible explanation for these results is that the populated municipalities at the edges of the A30 were already relatively accessible before the construction of the A30 (Barneveld is located close to the A1 between Amersfoort and Apeldoorn, and Ede is located close to the A12 between Utrecht and Arnhem). In fact, compared to the relatively high rates of improvement in accessibility (approximately 5.9-10.9\%) experienced in the A50 municipalities, the development of the highway improved accessibility levels only slightly more than $2.5 \%$ in the A30 area (see Table 2). This value is not notably different from the increase in accessibility in both control areas. This suggests that residents of these municipalities have not enjoyed increased accessibility from the construction of the A30 and perhaps the dominant effects in this area are those of increased traffic and noise pollution following the development of the highway.

Repeat sales: including externality levels

The second model specification includes direct estimation of the effects of each of the three externalities examined on the price of housing. The specification is as described in Eq. (3) and addresses the question of how home owners and residents of the region's municipalities value each of the highway externalities imposed by the development of the A30 and the A50 (see Table 5). Due to network effects, the development of the highways resulted in changes in accessibility levels throughout the study area. Therefore, this specification no longer makes use of the restricted treatment and control areas used previously. We begin by including only the positive accessibility effects in the model

Table 5 Estimation results from the repeat sales model: including externality levels

\begin{tabular}{|c|c|c|c|c|}
\hline Explained variable: $\log$ of price differences & (1) & & (2) & \\
\hline$\leq 300 \mathrm{~m}$ from the highway (noise) & & & $-0.0360 *$ & $(0.0218)$ \\
\hline log of changes in accessibility levels & $1.760 * * *$ & $(0.0780)$ & $1.765^{* * *}$ & $(0.0782)$ \\
\hline$\leq 1 \mathrm{~km}$ from interchange (traffic density) & & & $-0.0298 * *$ & $(0.0129)$ \\
\hline Year dummies & Yes & & Yes & \\
\hline Municipality and time period interaction dummies & Yes & & Yes & \\
\hline Observations & 269,129 & & 269,129 & \\
\hline R-squared & 0.820 & & 0.820 & \\
\hline
\end{tabular}

Standard errors in parentheses

$* * * \mathrm{p}<0.01 ; * * \mathrm{p}<0.05 ; * \mathrm{p}<0.1$ 
(Table 5, column 1). The reason for this is that a significantly larger number of properties are assumed to be influenced by accessibility effects compared to negative noise and traffic intensity effects. The negative effects are added later and are specified in column 2.

As expected, the coefficients of the changes in accessibility levels show strong positive values. The estimated elasticity between transaction price ratios and changes in accessibility levels is approximately 1.76 , which means that a change of $1 \%$ in accessibility levels is expected to result in a $1.76 \%$ increase in the transaction price ratio. The estimated value is robust and changes little when negative externalities are introduced in the model (column 2). As the increase in accessibility level in the municipalities along the A50 ranges from $5.9 \%$ to $10.9 \%$ (see Table 2), this increase translates to an approximate increase of $10-18 \%$ in the transaction price ratio. The estimated coefficient for changes in traffic density levels is also according to expectations and its value is estimated at approximately -0.0298 , implying that properties located within $1 \mathrm{~km}$ of a new interchange have also experienced a decline of approximately $3 \%$ in value. The noise pollution coefficient is also estimated to be negative and statistically significant at -0.0360 , indicating that properties in this range have experienced a decline of $3.6 \%$ in value.

The strong positive value of the accessibility coefficient indicates that for many properties, the improvement in accessibility is the dominant effect resulting from the development of the highways. Moreover, as some properties are exposed to multiple externalities, the positive accessibility effects can often offset the negative effects. This corresponds to the results of the single DID estimator specification (Table 4), in which the combined effect of the development project is found to be positive and significant.

Quasi-rents and marginal willingness-to-pay (WTP) analysis

The results of this specification can also be used to place monetary value on the development of the new highways. Following Mohring (1965), investment in transportation infrastructure development can be analyzed by the quasi-rents generated by the development project. This logic was applied by Klaiber and Smith (2010), who measured changes in capitalized housing prices to estimate the quasi-rents following highway segment additions. Focusing on the accessibility coefficient (Table 5, column 1), we are able to conduct a similar analysis and calculate households' WTP for accessibility improvement, which is defined as the change in housing price that would keep utility constant with any change in accessibility.

As changes in accessibility levels differ between postcodes, we begin by calculating the quasi-rents for the average property in each PC4 area. To obtain this, we multiply the estimated elasticity between price and accessibility with the average housing price in each PC4 area (in 2004, when the highways were completed), and the percentage of accessibility improvement that the area had experienced. Aggregated values are then calculated by multiplying the WTP values by the total housing supply in each PC4 area. The aggregation is undertaken under the assumption that all houses in a certain postal code area have experienced the same price effect due to the change in accessibility levels. As accessibility levels have increased relatively little in the municipalities along the A30, this analysis focuses on the A50 area.

In the municipalities located along the A50, significant changes in accessibility levels are observed. This corresponds with high WTP values per postal code in this area (see Table 6), which are found to range between $€ 19,000$ and $€ 66,000$. These values reflect a price increase equivalent to approximately $10-18 \%$ of the housing price. Examination of the aggregated WTP values reveals that the region's benefits from the highway 
Table 6 Average housing prices per PC4 in the A50 surrounding postal codes areas, and WTP for accessibility values

\begin{tabular}{|c|c|c|c|c|c|c|c|}
\hline Project & Municipality & Postcode & $\begin{array}{l}\text { Accessibility } \\
\text { change } \%\end{array}$ & $\begin{array}{l}\text { Mean price } \\
(€ \\
\text { thousand) }\end{array}$ & $\begin{array}{l}\text { Average } \\
\text { WTP (€ } \\
\text { thousand) }\end{array}$ & $\begin{array}{l}\text { Housing } \\
\text { supply }\end{array}$ & $\begin{array}{l}\text { Aggregate } \\
\text { WTP ( } € \\
\text { thousand) }\end{array}$ \\
\hline \multirow[t]{15}{*}{ A50 } & Uden & 5401 & 10.4 & 200.0 & 36.60 & 4,235 & 154,987 \\
\hline & Uden & 5402 & 10.3 & 218.7 & 39.74 & 3,220 & 127,948 \\
\hline & Uden & 5403 & 8.1 & 221.3 & 31.54 & 3,785 & 119,378 \\
\hline & Uden & 5404 & 11.0 & 338.5 & 65.36 & 1,685 & 110,134 \\
\hline & Uden & 5406 & 10.1 & 275.2 & 48.80 & 1,920 & 93,700 \\
\hline & Volkel & 5408 & 6.6 & 257.8 & 29.99 & 1,305 & 39,140 \\
\hline & Veghel & 5463 & 6.0 & 185.7 & 19.63 & 2,805 & 55,074 \\
\hline & Veghel & 5464 & 8.1 & 281.7 & 40.12 & 2,130 & 85,460 \\
\hline & Veghel & 5465 & 8.9 & 320.0 & 50.04 & 605 & 30,276 \\
\hline & Veghel & 5466 & 9.8 & 384.6 & 66.12 & 565 & 37,356 \\
\hline & Veghel & 5467 & 5.88 & 204.8 & 21.20 & 3,100 & 65,730 \\
\hline & $\begin{array}{l}\text { Sint } \\
\text { Oedenrode }\end{array}$ & 5491 & 6.7 & 230.1 & 27.23 & 4,000 & 108,908 \\
\hline & $\begin{array}{l}\text { Sint } \\
\text { Oedenrode }\end{array}$ & 5492 & 6.3 & 235.0 & 25.93 & 3,085 & 79,997 \\
\hline & Son & 5691 & 7.3 & 307.0 & 39.63 & 4,280 & 169,618 \\
\hline & Total A50 & & & & & 36,720 & $1,277,707$ \\
\hline \multicolumn{6}{|c|}{ WTP per km of highway ('000) } & & 37,580 \\
\hline
\end{tabular}

development are estimated to be approximately $€ 1,277$ million. When the length of the A50 is taken into consideration, the benefits from the projects become comparable to other previous findings. The length of the developed A50 segment is $34 \mathrm{~km}$ and therefore the benefits per developed $\mathrm{km}$ are equivalent to approximately $€ 37.5$ million. These values show some similarity with those found by Klaiber and Smith (2010), which were estimated at US\$73 million to US\$273 million per mile (or approximately $€ 30$ million to $€ 125$ million per $\mathrm{km}$ of additional highway).

Repeat sales: including externality levels and neighborhood effects

As municipalities and neighborhoods are assumed to be heterogeneous, it is possible that the marginal effects of each of the externalities are also different between them. The purpose of the model that is specified in Eq. (4) is to check for differences in neighborhood effects by creating interaction variables between each of the 30 municipalities in the treatment area and the changes in levels of externalities (see Table 7). It should be highlighted that as the number of available observations is relatively low, a biased estimator is probable in many municipalities. Also, some municipalities in the treatment area are not exposed to the negative highway externalities at all. Only four municipalities include multiple properties within $300 \mathrm{~m}$ of the highway (Barneveld, Son, Sint Oedenrode, and Uden) and seven municipalities include properties within $1 \mathrm{~km}$ of a new interchange (Barneveld, Ede, Lunteren, Son, Sint Oedenrode, Uden, and Veghel). This makes it difficult to undertake a proper comparison of the marginal effects of traffic and noise pollution levels on the prices of houses in different municipalities. 
Table 7 Estimation results from the RS model: including externalities and neighborhood effects per municipality

\begin{tabular}{lllll}
\hline Explained variable: log of transaction price differences & & $(1)$ & \\
\hline Log of changes in accessibility levels & A30 & Barneveld & -0.157 & $(0.142)$ \\
& & Bennekom & 0.130 & $(0.189)$ \\
& & Lunteren & $0.527^{*}$ & $(0.291)$ \\
& A50 & Son & $0.531^{* * *}$ & $(0.0736)$ \\
& & Sint Oedenrode & $0.553^{* * *}$ & $(0.125)$ \\
& & Veghel & $0.682^{* * *}$ & $(0.160)$ \\
& & Uden & $1.139^{* * *}$ & $(0.218)$ \\
& & Volkel & $1.406^{* * *}$ & $(0.372)$ \\
$\leq 300$ m from the highway (noise) & A50 & Uden & $-0.0602^{* *}$ & $(0.0301)$ \\
$\leq 1$ km from interchange (traffic density) & A50 & Uden & $-0.0542^{*}$ & $(0.0329)$ \\
Year dummies & & & Yes & \\
Control area municipalities interaction variables & & & Yes & \\
Observations & & & 269,129 & \\
R-squared & & & 0.818 & \\
\hline
\end{tabular}

Standard errors in parentheses

$* * * \mathrm{p}<0.01 ; * * \mathrm{p}<0.05 ; * \mathrm{p}<0.1$

As expected, the municipality-specific coefficients for changes in accessibility are positive and significant for the A50 municipalities, and their values vary between 0.53 and 1.41 , which fits with the results of the previous estimation. The estimated values show that accessibility elasticities are different in each municipality, probably due to unobserved heterogeneity in preferences or spatial characteristics in each town. As mentioned above, it is possible that some of the results may be biased due to the low number of observations. Interestingly, the values of accessibility coefficients in the A50 area increase from the south of the A50 (Son) to the north (Volkel). This may suggest that although A50 municipalities have experienced different levels of improvement in accessibility from the highway network perspective, the effects are valued higher in towns in which accessibility to Eindhoven has been improved in particular, most likely as it is the largest employment center in the province.

Among the A30 municipalities, the estimated values in the municipalities of Barneveld and Bennekom are statistically insignificant, which supports the argument presented earlier that the development of the A30 has not significantly improved accessibility in these municipalities, and that it is likely rather to be correlated with increased exposure to negative externalities. Unlike Barneveld and Bennekom, the town of Lunteren presents a positive and significant coefficient at the $10 \%$ level. This might be explained by the location of Lunteren. As Lunteren is located at the center of the A30 and was not previously connected to a major highway, it is possible that the inhabitants of Lunteren attached positive values to the improvement in accessibility that resulted from the development of the A30, unlike those of other municipalities in the area.

Due to the lack of observations, the only municipality in which an interpretation of the noise pollution coefficient can be provided is Uden, where the noise coefficient is estimated based on 54 observations (see Table 5). The results in Table 5 show that the estimated value of the noise coefficient is significant and negative at $-6.0 \%$, indicating that properties at this proximity to the A50 in Uden are valued negatively compared to the rest of the 
sample. Uden is also the only town in which a sufficient number of transactions occurred within $1 \mathrm{~km}$ of a new A50 interchange and thus the traffic density effect can be estimated. As expected, the estimated value is negative at $-5.4 \%$, statistically significant at the $10 \%$ level.

The results of the model specifications provide several important findings. The first model confirms that the total effect of highway development on the price of housing is not only positive, but also salient, and may even be stronger during the period before the project ends. The implicit conclusions are that for most properties in the vicinity of the highway, the positive externalities are more dominant than the negative ones, and these positive effects on the local housing markets are capitalized long before the end of construction. The second model separates the effect of the development of the highways into the three major externalities examined and estimates the value of each of these from the perspective of the public. The results show a positive valuation for improved accessibility, and aversion related to noise pollution and traffic intensity. Finally, the results of the specification that addresses the issue of neighborhood heterogeneity in relation to externality effects show that price-accessibility elasticities are not constant. Although mostly positive, the values of elasticities may depend on unobserved heterogeneity between the spatial characteristics of the towns or the preferences of the inhabitants in each town.

\section{Conclusions and discussion}

In this paper, we have explored the effects of transportation infrastructure development on the price of housing. To estimate these effects, we apply three different specifications of the repeat sales model. In the estimation process, we control for each highway externality separately, neighborhood effects, and anticipation effects. The findings support our expectations. Improved accessibility is found to be valued positively, whereas noise and traffic intensity are found to affect housing prices negatively. In most properties in the treatment area, the combined effect of the three externalities is found to be positive, as reflected in the overall average increase in the transaction prices of houses. This implies that the positive value attributed to improved accessibility levels is greater than the negative values attributed to increased noise pollution and traffic intensity levels.

The results obtained in this research may be used primarily in a wider social cost benefit analysis to evaluate whether the development of the roads has been successful from a social perspective and whether the two projects have increased social welfare in their nearby municipalities. As mentioned above, changes in the price of housing reflect the residents' and homeowners' monetary valuation of a newly developed project and therefore they are a key issue in determining changes in social welfare that result from it. However, it is worth noting that although the results presented here are important in determining whether a highway development has been successful from a social perspective, certain other issues should also be considered when addressing this matter. As demonstrated in the case of the A30, negative and insignificant results may appear to imply negative evaluations of the highway. However, the project cannot be regarded as socially unsuccessful only based on results that relate to its immediate surroundings. This highway is likely to have been beneficial in other ways, such as relieving traffic congestion between the east of the Netherlands and the large labor market in the Randstad. A network improvement in accessibility and traffic congestion is unlikely to be reflected in the price of housing in remote areas as not all inhabitants in more distant locations participate in the Randstad labor market and thus the effects on housing prices are expected to be less 
noticeable. This means that future research should ideally consider wider transportation network effects in the assessment process of changes in social welfare.

The results reported here may also be useful in regional policy. For example, the estimation results and willingness-to-pay (WTP) values may be used in value setting for future similar highway developments in nearby areas. It is likely that for those in close geographic proximity, spatial and socio-demographic factors are relatively similar and the valuation of the three different externalities will resemble the estimated values obtained from the towns in our study area. In this respect, future research may examine differences in willingness-to-pay over different population groups, by considering heterogeneity in household characteristics (Bajari and Benkard 2005; Bajari and Kahn 2005). Given data availability, such analysis can also shed light on the sorting process that is initiated by the development of the new highways, and to track the demographic change in neighborhoods which may result from this process (Bayer et al. 2004; Bayer and Timmins 2005).

Moreover, our results may also be used as a reference for a second-best compensation mechanism, which may be applied to maximize the social gain from the development project. For example, specific taxes can be levied in areas with high increases in property prices to help finance the development project or to provide additional infrastructure investments. Such additional investments may include noise barriers, improvement of traffic conditions near interchanges, or directing compensation to the inhabitants and homeowners in areas where the development project causes a reduction in house prices and social welfare. Such a solution minimizes the welfare loss in areas that do not benefit from the development project and therefore might improve social welfare in these areas.

Acknowledgments We would like to thank Ronnie Lassche for his significant contribution in constructing the travel time database that formed the basis of the accessibility measure used in this paper. We thank Kadaster, the Dutch land registry, for providing us with high quality data and insightful advice on study locations and development projects. We would also like to thank the participants of the Dutch-Israeli regional science workshop for a constructive discussion on the research.

Open Access This article is distributed under the terms of the Creative Commons Attribution License which permits any use, distribution, and reproduction in any medium, provided the original author(s) and the source are credited.

\section{Appendix}

\section{Appendix 1}

See Figs. 1, 2, and 3; Tables 8 and 9

Table 8 Dates of opening of the A50: Eindhoven-Uden

\begin{tabular}{llcl}
\hline From & To & Length (Km) & Open \\
\hline Sint Oedenrode & Veghel & 7 & 4 July 2003 \\
Veghel & Uden-Noord & 10 & 8 September 2003 \\
Ekkersrijt (Eindhoven) & Nijnsel (Sint Oedenrode) & 6 & 11 September 2003 \\
Nijnsel (Sint Oedenrode) & Sint Oedenrode & 2 & 4 June 2004 \\
A50 lane configuration & & & Length \\
\hline From & To & Lane configuration & $34 \mathrm{~km}$ \\
\hline Ekkersrijt (Eindhoven) & Paalgraven (Oss) & $2 \times 2$ & \\
\hline
\end{tabular}


Table 9 Dates of opening of the A30: A1-Maanderbroek

\begin{tabular}{llcr}
\hline From & To & Length $(\mathrm{km})$ & Open \\
\hline A1 (Barneveld) & Lunteren & 10 & 1972 \\
Lunteren & Ede-Kernhem & 5 & 4 October 2003 \\
Ede-Kernhem & A12 (Maanderbroek) & 2 & 12 July 2004 \\
A30 Lane configuration & & Lane configuration & Length \\
\hline From & To & $2 \times 2$ & $18 \mathrm{~km}$ \\
\hline Maanderbroek & Barneveld & $2 \times 2$ & \\
\hline
\end{tabular}

Study area and highway development plan details

The study area includes the five south-eastern provinces of the Netherlands: Limburg, Noord-Brabant, Gelderland, Flevoland, and Utrecht (excluding the city of Utrecht itself).

The description of the highway-specific treatment areas is further elaborated under each highway's project description.

\section{A50 (Eindhoven-Oss)}

Rijksweg A50 is a highway that stretches $151 \mathrm{~km}$ between Emmeloord and Eindhoven, in the east of the Netherlands (see Fig. 2). Its southern $34 \mathrm{~km}$ stretch, between Oss and Eindhoven, in the province of Noord-Brabant, was constructed in the period 2000-2006. The southern part between Eindhoven and Uden was constructed first as a new road that bypasses the small towns north of Eindhoven rather than running through the town centers. The southern part of the project was completed in June 2004. The treatment area for the A50 includes house transactions that took place after the year 2004 in the municipalities of Uden, Veghel, Sint Oedenrode, Son, and Volkel, all of which are adjacent to the A50, or located at a maximum distance of $4 \mathrm{~km}$ from it.

The highway development process is presented in Table 8 .

\section{A30 (Barneveld-Maanderbroek)}

Rijksweg A30 is a highway that stretches $18 \mathrm{~km}$ between Barneveld and Maanderbroek (Ede), in the Dutch province of Gelderland (see Fig. 3). The northern $10 \mathrm{~km}$ stretch of the highway was initially opened in 1970 as a $2 \times 2$ road between Barneveld and Lunteren. The southern part was also opened in 1970 , but consisted of a small $2 \times 1$ road that connected Lunteren and Ede Noord. In the period 2003-2004, the highway underwent a development work that included constructing a final stretch to Maanderbroek and adding a southern access from Rijksweg A12, as well as broadening the highway to $2 \times 2$ lanes throughout its length. The construction works were completed in July 2004.

Based on the development project's geographic area and time schedule, the definition for the treatment area for the A30 includes house transactions that took place after the year 2004 in the municipalities of Ede, Barneveld, Lunteren, and Bennekom, all of which are adjacent to the $\mathrm{A} 30$, or located at a maximum distance of $5 \mathrm{~km}$ from it.

The highway development can be divided into three parts, as indicated in Table 9: 
Appendix 2

Price indexes

See Fig. 4

Appendix 3

See Figs. 5 and 6

\section{Changes in levels of accessibility and regional exposure to externalities}

These maps show a graphic depiction of the differences in accessibility levels in each municipality before and after the completion of the A30 and the A50. The accessibility scores were computed using the economic potential activity indicator with the parameter alpha $=1$. The map clearly shows how the municipalities along the A50 and A30 have experienced the sharpest increases in accessibility compared to the rest of the Netherlands.

The chart below shows the exposure to negative externalities in properties in the municipality of Uden. Properties were considered to be exposed to changes in levels of noise pollution within the vicinity of $300 \mathrm{~m}$ from the new A50 and to traffic density within $1 \mathrm{~km}$ of a new interchange. Changes in accessibility levels are not shown on this map, but are specified in Fig. 5.

\section{Appendix 4}

See Fig. 7

Difference-in-differences (DID) model study area scenarios

\section{References}

Alonso, W.: Location and Land Use. Toward a General Theory of Land Rent. Harvard University Press, Cambridge (1964)

Armstrong, R.J., Rodríguez, D.A.: An evaluation of the accessibility benefits of commuter rail in eastern Massachusetts using spatial hedonic price functions. Transportation 33(1), 21-43 (2006)

Bailey, M., Muth, R., Nourse, H.: A regression method for real estate price index construction. J. Am. Stat. Assoc. 58(304), 933-942 (1963)

Bajari, P., Benkard, C.L.: Demand estimation with heterogeneous consumers and unobserved product characteristics: a hedonic approach. J. Polit. Econ. 113(6), 1239-1276 (2005)

Bajari, P., Kahn, M.E.: Estimating housing demand with an application to explaining racial segregation in cities. J. Bus. Econ. Stat. 23(1), 20-33 (2005)

Bayer, P., Ferreira, F., McMillan. R.:Tiebout sorting, social multipliers and the demand for school quality. No. w10871. National Bureau of Economic Research (2004)

Bayer, P., Timmins, C.: On the equilibrium properties of locational sorting models. J. Urban Econ. 57(3), 462-477 (2005)

Bruinsma, F., Rietveld, P.: The accessibility of European cities: theoretical framework and comparison of approaches. Environ. Plan. A 30(3), 499-521 (1998)

Case, K., Shiller, R. Prices of single family homes since 1970: new indexes for four cities (1987)

Cheshire, P., Sheppard, S.: On the price of land and the value of amenities. Economica 62(246), 247-267 (1995)

Cotteleer, G., Peerlings, J.H.M.: Spatial planning procedures and property prices: the role of expectations. Landsc. Urban Plan. 100(1-2), 77-86 (2011) 
Coulson, N., Engle, R.: Transportation costs and the rent gradient. J. Urban Econ. 297, 287-297 (1987)

Debrezion, G., Pels, E., Rietveld, P.: The impact of railway stations on residential and commercial property values: a meta-analysis. J. Real Estate Financ. Econ. 35, 161-180 (2007)

Franklin, J. P., Waddell P.: A hedonic regression of home prices in King County, Washington, using activity-specific accessibility measures. In: Proceedings of the Transportation Research Board 82nd Annual Meeting, Washington, DC (2003)

Gutiérrez, J.: Location, economic potential and daily accessibility: an analysis of the accessibility impact of the high-speed line Madrid-Barcelona-French border. J. Transp. Geogr. 9(4), 229-242 (2001)

Gutiérrez, J., Condeço-Melhorado, A., Martín, J.C.: Using accessibility indicators and GIS to assess spatial spillovers of transport infrastructure investment. J. Transp. Geogr. 18(1), 141-152 (2010)

Henneberry, J.: Transport investment and house prices. J. Prop. Valuat. Invest. 16(2), 144-158 (1998)

Iacono, M., Levinson, D.: Location, regional accessibility, and price effects. Transp. Res. Rec.: J. Transp. Res. Board 2245(1), 87-94 (2011)

Imbens, G.W., Wooldridge, J.M.: Recent developments in the econometrics of program evaluation. J. Econ. Lit. 47(1), 5-86 (2009)

Kim, K.S., Park, S.J., Kweon, Y.-J.: Highway traffic noise effects on land price in an urban area. Transp. Res. Part D: Transp. Environ. 12(4), 275-280 (2007)

Klaiber, H. A., Smith, V. K. Valuing incremental highway capacity in a network. National Bureau of Economic Research Working Paper, 15989 (2010)

Koster, H.R.A., Van Ommeren, J.N., Rietveld, P. :Estimating the benefits of improved rail access: geographical range and anticipation effects. Tinbergen Institute Discussion Paper (2010)

López, E., Gutiérrez, J., Gómez, G.: Measuring regional cohesion effects of large-scale transport infrastructure investments: an accessibility approach. Eur. Plan. Stud. 16(2), 277-301 (2008)

Martínez, L.M., Viegas, J.M.: Effects of transportation accessibility on residential property values. Transp. Res. Rec: J. Transp. Res. Board 2115(1), 127-137 (2009)

Mohring, H.: Urban highway investments. In: Measuring benefits of government investments, Brookings, Washington, DC, 231-291 (1965)

Nelson, J.P.: Highway noise and property values: a survey of recent evidence. J. Trans. econ. policy 16, 117-138 (1982)

Ossokina, I., Verweij, G.: Quasi-experimental evidence on the effect of traffic externalities on housing prices. CPB Netherlands Bureau for Economic Policy Analysis (2011)

Rosen, S.: Hedonic prices and implicit markets: Product differentiation in pure competition. J. Polit. Econ. 82(1), 34-55 (1974)

Smersh, G.T., Smith, M.T.: Accessibility changes and urban house price appreciation: a constrained optimization approach to determining distance effects. J. Hous. Econ. 9(3), 187-196 (2000)

Spiekermann, K., Neubauer, J.: European accessibility and peripherality: concepts, models and indicators. Nordregio WP, 9, 43 (2002)

Theebe, M.A.J.: Planes, trains, and automobiles: the impact of traffic noise on house prices. J. Real Estate Financ. Econ. 28(2-3), 209-234 (2004)

Tillema, T., Hamersma, M., Sussman, J.M., Arts, J.: Extending the scope of highway planning: accessibility, negative externalities and the residential context. Transp. Rev. 32(6), 745-759 (2012)

Vickerman, R., Spiekermann, K., Wegener, M.: Accessibility and economic development in Europe. Reg. Stud. 33(1), 1-15 (1999)

Wang, F.T., Zorn, M.: Estimating house price growth with repeat sales data: what's the aim of the game? J. Hous. Econ. 6(2), 93-118 (1997)

Wilhelmsson, M.: The impact of traffic noise on the values of single-family houses. J. Environ. Plan. Manag. 43(6), 799-815 (2000)

Yiu, C.Y., Wong, S.K.: The effects of expected transport improvements on housing prices. Urban Stud. 42(1), 113-125 (2005)

RWS (2008). Highway noise pollution report. Available from: http:/www.rijkswaterstaat.nl/images/ Actieplan\%20omgevingslawaai\%20rijkswegen\%202008_tcm174-205638.pdf [accessed: April 7, 2014]

RWS (2012). Highway noise pollution maps. Available from: http://www.rijkswaterstaat.nl/wegen/natuur_ en_milieu/geluid_rond_snelwegen_nederland/geluidskaart/ [accessed: April 7, 2014]

Or Levkovich is currently a Ph.D. student at the department of Spatial Economics at VU University Amsterdam. His research interests include the relationship between transport infrastructure development and urban growth, location choices of economic agents and valuation of spatial amenities. 
Jan Rouwendal is a professor at the department of Spatial Economics of VU university. He graduated at Erasmus University Rotterdam in 1983 and received his Ph.D. at the VU University Amsterdam on a thesis about discrete choice models and housing market analysis. He is affiliated as a research fellow to the Tinbergen Institute and Netspar.

Ramona van Marwijk is a senior advisor at The Netherlands' Cadastre, Land Registry and Mapping Agency. She is responsible for research and tailor made consulting services focusing on real estate and land issues, such as housing market developments, land and property values, land use and spatial information. She holds a Ph.D. in Socio-Spatial Research. 